\title{
Releitura do diagrama "Domínios da Cultura do Design" para a análise das imagens-mensagens dissidentes do Instagram
}

\author{
Adaptation of the diagram "Domains of Design Culture" for the analysis of \\ dissenting Instagram images-messages.
}

Didiana Prata

design de comunicação, análise de imagens, mídias digitais, cultura visual, design de informação

O objetivo deste artigo é apresentar uma releitura do diagrama "Domínios da Cultura do Design", criado por Guy Julier, em 2006, para analisar as postagens das mídias digitais a partir da visão interdisciplinar da cultura do design. Derivada da cultura visual, esta linha de estudos contribui para a compreensão das imagens contemporâneas, em particular, das imagens dissidentes que circulam no Instagram. Estas representam narrativas visuais temáticas dos acontecimentos políticos no Brasil nos últimos dois anos, por meio de uma linguagem visual muito específica. A aplicação do diagrama, norteada pelas referências teóricas de Julier e de outros autores, resultou no apontamento de quatro pontos fundamentais para a investigação das peças gráficas como um sistema de design de informação: circulação da imagemmensagem; experiência do usuário no ciberespaço; contextualização social; memória afetiva e gráfica. Esta proposta de uma nova nomenclatura para as intersecções do diagrama original de Julier poderá ser útil para outras pesquisas sobre design de comunicação e narrativas visuais digitais, ampliando a discussão sobre cultura visual e memória gráfica brasileira na atualidade.

communication design, image analyses, digital media, visual culture, information design

The purpose of this text is to present a reinterpretation of the diagram "Domains of the Design Culture", created by Guy Julier, in 2006, to analyse socialmedia production by an interdisciplinarity of the fields in Design Culture. Derived from Visual Culture studies, it contributes as a good methodology to the analysis of contemporary images - more specifically, dissent images that circulate on Instagram. These imageries represent thematic visual narratives of political events in Brazil in the past two years, through a unique language. The application of this diagram, guided by Julier's and other authors' references, resulted in the addition of four fundamental points for the investigation of these graphic pieces as an information design system: circulation of the image-message; user experience in cyberspace; social contextualization; affective and graphic memory. The proposal of a new nomenclature for diagram intersections in this study may also be applied to other researches on communication design, on new formats of digital visual narratives, thus expanding the discussion on Brazilian visual culture and graphic memory today.

\section{Introdução}

O desafio desta breve investigação é propor uma adaptação do diagrama "Domínios da Cultura do Design”, idealizado por Guy Julier (2006), pesquisador e professor de design da Universidade Aalto em Helsinki. Criada para ilustrar os campos de atuação interdisciplinares da

Anais do $10^{\circ} \mathrm{CIDI}$ e $10^{\circ} \mathrm{CONGIC}$

Kelli C.A.S. Smythe, Rafael de Castro Andrade (orgs.)

Sociedade Brasileira de Design da Informação - SBDI

Curitiba | Brasil | 2021
Proceedings of the $10^{\text {th }} \mathrm{CIDI}$ and $10^{\text {th }}$ CONGIC

Kelli C.A.S. Smythe, Rafael de Castro Andrade (orgs.)

Sociedade Brasileira de Design da Informação - SBDI Curitiba | Brazil | 2021 
sua linha de estudo sobre a cultura do design, essa metodologia se mostrou aplicável à análise de imagens digitais que circulam nas redes sociais, pela lente do design gráfico.

O objeto de análise será um conjunto de imagens dissidentes publicadas no Instagram "dissidentes" aqui se referindo às estratégias de agenciamento das quais se valem grupos temporários que se organizam em torno de pautas comuns. Essas manifestações efêmeras, de cunho ativista, revelam novas estéticas da memória no século 21 (Beiguelman, 2019) e constituem dados da memória gráfica brasileira (Braga \& Farias, 2018), do design nacional e da nossa história. As imagens selecionadas representam os principais acontecimentos socioculturais e políticos ocorridos durante as eleições presidenciais brasileiras de 2018 e o primeiro ano da gestão do presidente Jair Bolsonaro.

Esse conjunto de imagens publicadas pelo público, em paralelo aos acontecimentos políticos e às manifestações nas ruas, faz parte de uma ampla coleta de dados da produção gráfica brasileira durante esse período. São imagens extraídas do fluxo midiático da rede por meio da metodologia de visualização de dados (Vesna, 2007), a partir da qual foram selecionadas algumas hashtags - como \#desenhospelademocracia, \#designativista, \#mariellepresente, entre outras - para compor uma base de dados representativa da linguagem visual das redes. ${ }^{1}$

Esse tipo de imagem da rede é conhecido no campo do design de comunicação como card - pequeno objeto gráfico e interativo composto por informações textuais e visuais (fotografias ou ilustrações) resumidas e de fácil compreensão, publicado no formato quadrado, padrão do aplicativo Instagram. As imagens representam produções gráficas heterogêneas, feitas muitas vezes com os recursos tecnológicos dos aplicativos nos quais são editadas e publicadas. Criadas para serem veiculadas no calor dos acontecimentos políticos, carregam em sua mensagem visual e verbal elementos que vão além do estritamente formal ou visual, pois representam e traduzem, nas redes, os acontecimentos das ruas.

Os cards serão denominados nesta investigação imagens-mensagens, devido a suas características formais e contextuais. Pela natureza híbrida das imagens-mensagens das redes, é difícil classificá-las e analisá-las com base em uma única linha de estudo. São peças gráficas produzidas para circular em ambientes informacionais, em dispositivos móveis, em tempo real e em rede e que, ao se deslocarem, estão sujeitas a modificações. A circulação no fluxo midiático gera a inserção de novos elementos visuais, aplicados por outros autores, também usuários das redes. Os cards representam novas linguagens visuais que merecem ser estudadas no contexto da cultura do design.

\footnotetext{
${ }^{1}$ O arquivamento, a organização e a classificação estética dessas imagens das redes, à luz do design gráfico e da visualização de dados, compõem a pesquisa de doutorado da autora, orientada pela Profa Giselle Beiguelman, no Curso de Pós-graduação em Design na FAU-USP, que pode ser mais bem compreendida a partir do experimento gráfico "Calendário dissidente: cultura visual e memória gráfica brasileira" (www.calendariodissidente.fau.usp.br).
} 


\section{Uma atualização da cultura visual}

A linha de estudos da cultura do design proposta por Julier (2006) busca complementar alguns atributos relacionados à análise da imagem, apresentando uma nova camada interpretativa à teoria da cultura visual (Mirzoeff ,1995) - amplamente adotada no campo da iconologia no período pré-internet 2.0 e aplicada em inúmeros estudos da produção artística e cultural desde o final dos anos 1970 até hoje. Essa teoria foi atualizada e gerou derivações por meio do trabalho de outros pesquisadores além de Julier, como o brasileiro Ulpiano Menezes (2003) e a americana Alexis Boylan (2020), para citar apenas alguns dos autores que a elegeram como linha de estudos.

No entanto, ao passo que o foco principal de tais investigações está nos atributos visuais da imagem estática - composição, estrutura, perspectiva, signos e interpretação semiótica, linguagem verbal -, Julier (2006) faz uma crítica à análise de imagem por um viés puramente "visual", apontando o contexto informacional e social e a fruição estética do espectador como elementos de análise essenciais na contemporaneidade. No artigo intitulado From Visual Culture to Design Culture, onde foi publicado o diagrama "Domínios da Cultura do Design", ele se propõe ir além da visualidade. Reconhece, entretanto, a importância de questões tratadas antes por Mirzoeff (1995), como a repercussão da "virada visual" da sociedade ocidental moderna no campo do design; como a relação entre o consumo de massa e a vasta produção e circulação de imagens em meados do século XX (pós-período industrial) (Julier, 2006). Tais imagens, de natureza mais comercial e comunicacional, apresentam outras características das imagens das artes e da ciência. Os novos meios de produzir e veicular arte para um "mercado" crescente e amador passou a exigir, desde então, mais apuro visual das peças gráficas, cada vez mais elaboradas devido às novas possibilidades de reprodutibilidade técnica.

O paralelo entre a evolução da linguagem visual e o desenvolvimento das possibilidades técnicas permeia toda a história do design, na qual a tecnologia estimula muitas experimentações gráficas, sobretudo no campo da comunicação, resultando no surgimento de novas estéticas. Para Julier, o crescimento de outras linguagens decorrentes das novas tecnologias, como animação, fotografia e audiovisual, e a interdependência de tecnologias visuais, mídias convergentes e experiências simultâneas - a mesma informação visual é gerada e distribuída para plataformas diversas como câmeras celulares, de DVD, webcams, TV LED etc. - são pontos fundamentais para entendermos a imagem digital.

O diagrama "Domínios da Cultura do Design" (Figura 1), de 2006, é resultado de uma evolução do pensamento sistêmico do autor. Em 2002, ele já havia publicado seu primeiro diagrama, no qual predominava a tríade designer, produção e consumo como condicionantes para o estudo do campo da cultura do design. O consumo do design é um tema pesquisado por Julier até os dias de hoje e se mantém como tema central na órbita da circulação, do valor e da prática do design. 
Figura 1: Diagrama “Domínios da Cultura do Design”, de Guy Julier (2006), colorido para este artigo

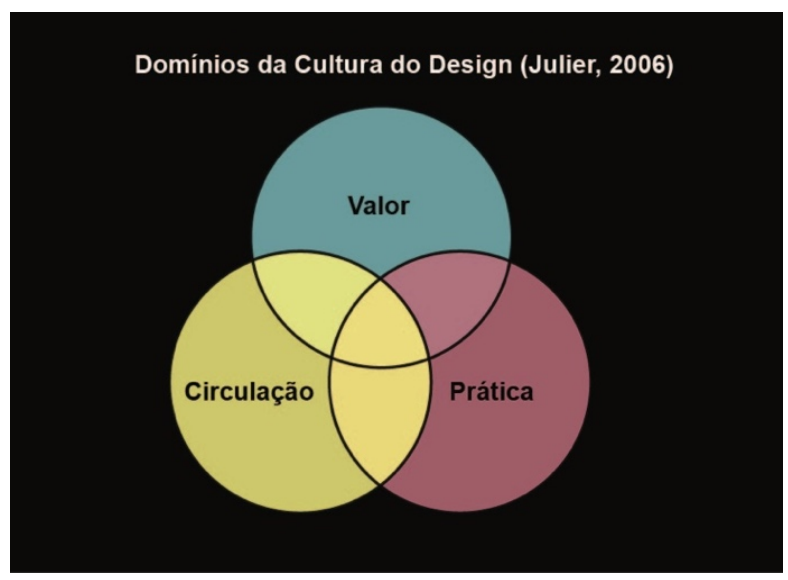

Nesse diagrama, Julier incorpora o pensamento do historiador do design Victor Margolin, para quem o artefato material (ou a peça gráfica) deve ser analisado a partir das condições dos meios de produção, das atividades e dos serviços que o envolvem. Os objetos gráficos são, para Margolin (1995 apud Julier, 2006, p.73), agregadores de contexto social.

Com o apoio desse novo modelo de análise, Julier se propõe compreender a dinâmica e os efeitos das relações materiais e imateriais que são articuladas por diferentes atores (designers, consumidores) e através de múltiplos artefatos da cultura do design. As imbricações entre as relações materiais e imateriais estão sugeridas pela intersecção dos conjuntos, abrindo a outras possibilidades. A configuração dos três domínios inter-relacionados (Circulação, Valor e Prática) se apresentou como um caminho interessante para a análise das imagens-mensagens das redes.

\section{Adaptações ao diagrama original de Julier}

A fim de experimentar o diagrama de Julier como método de estudo do design de informação relacionado às mídias digitais e testar sua aplicação na análise de imagens da rede, sugerimos adaptações a ele, com a criação de uma nomenclatura para as intersecções dos três domínios originais. É importante citar que essa nomenclatura se baseou nos conceitos originais do autor para definir a linha de estudos sobre a cultura do design (2006). Neste projeto, procurou-se adaptar esses termos a fim de aplicá-los no estudo dos cards das redes.

\section{Circulação}

No diagrama de Julier, Circulação se refere a atributos relacionados à reprodutibilidade técnica da peça gráfica. No ambiente digital das redes, a reprodutibilidade é infinita, pois as postagens são repostadas pelos usuários e deslocadas para outros contextos, diferentes daqueles em que foram originalmente criadas para circular.

Com o uso de estratégias de tagueamentos (as hashtags que precedem as palavras-chaves nas legendas das imagens do Instagram), há um deslocamento e novas possibilidades de 
inserção de uma mesma imagem em diferentes narrativas. Essa imagem está em constante transformação e sujeita à interação e interpretação do usuário, à sua experiência da "visualidade" do fluxo das imagens nas redes. A estética da narrativa, assim como a estrutura visual da imagem e o seu entendimento, parece oscilar de acordo com essas combinações de dados e de ações colaborativas por parte dos "espectadores-autores-artistas" participativos (Paul, 2011).

Os recursos tecnológicos dos próprios aplicativos nos quais as imagens circulam - 0 Instagram, no presente caso - também motivam e "seduzem" o usuário a produzir imagens em baixa resolução, comprimidas, "feitas para viajar" (Steyerl, 2005). O aplicativo contém uma série de filtros que influenciam a estética "fast food" de certos cards e permitem o acesso e participação de todo o público da rede na produção estética ativista.

\section{Participação do usuário e espectador}

$\mathrm{Na}$ análise dos cards, a participação do usuário, seu engajamento, likes e repostagens com novas palavras-chaves, representa uma parte fundamental no diagrama, na intersecção entre Circulação e Prática (Figura 2). As questões relacionadas à interação do espectador levantam outros fenômenos igualmente relevantes, como a diluição do autor, a apropriação de imagens de outras fontes e os jogos de linguagem. São novos regimes de visibilidade, como aponta Julier (2006) e, também, outros autores do campo da filosofia, da história da arte e da artemídia, como Rancière, Didi-Huberman e Oliver Grau².

Figura 2: Intersecção do diagrama nomeada como "Participação do usuário e espectador"

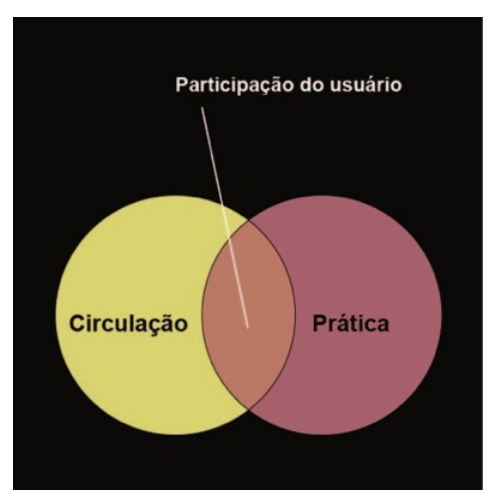

\section{Prática}

Para Julier, o domínio da Prática considera a ação e a recepção dos artefatos materiais.

Contempla todos os criativos que concebem sua arte para circular nas redes: designers,

\footnotetext{
${ }^{2}$ A discussão sobre o novo status da imagem pode ser aprofundada a partir desses três autores. Com uma abordagem filosófica, Rancière discorre sobre o novo regime das artes em O destino das imagens (2013). Didi-Huberman faz uma análise a partir da história da arte, reforçando a interação entre o espectador e o objeto de arte no espaço em $O$ que nos vemos, o que nos olha (1998). Oliver Grau, em Imagery in the 21st Century (2013), trata da evolução da imagem desde o audiovisual e da evolução das novas mídias. Essas conceituações interdisciplinares servem de base para estudar as imagens em aspectos que vão além do visível.
} 
artistas, cidadãos que, envolvidos com os acontecimentos políticos, criam novas estratégias de linguagem para se comunicarem por meio da imagem, por meio de uma peça gráfica, denominada aqui imagem-mensagem ou card.

Para esta pesquisadora, a Prática também inclui a atividade do usuário do Instagram, que se identifica com a causa e com a estética do card, se apropria da imagem, acrescenta-lhe novas informações ou elementos visuais e volta a postá-la. Essa prática do receptor faz com que ele se torne o ator de uma nova ação - ação essa que contribui para a estética desses posts com acréscimos de frases, ilustrações ou apenas novos significados à medida que são deslocados e recolocados em circulação em um outro contexto. A adição de imagens de diversas fontes, em um remix de imagens ${ }^{3}$ apropriadas, caracteriza a prática da produção estética para as redes.

A estratégia de colagem, justaposição de referências temporais e apropriação explícita de imagens ocorre desde a pop arte e foi muito usada pelo movimento punk no final dos anos 1970, ganhando força novamente no mundo digital pela facilidade do acesso às referências iconográficas na web. As novas formas de produção de linguagem, a justaposição e fusão de elementos visuais de diferentes fontes dão origem a fake images, imagens ficcionais.

Colaboração e coletividade caracterizam esse processo criativo.

Exemplos dessa estética encontram-se na prática ativista de movimentos coletivos organizados em torno de hashtags temáticas como "ele não", "me too", "marielle presente", "fora garimpo fora covid", "aquecimento global", "vidas negras importam", para citar apenas alguns.

No domínio Prática do diagrama, essa produção dissidente é entendida como uma prática estética, uma produção de linguagem que responde aos anseios de criadores, consumidores/espectadores e cidadãos informatizados que participam e se comunicam por meio da rede Instagram.

\section{Valor}

No território Valor, podemos analisar todo o contexto sociopolítico no qual essas imagensmensagens são criadas. O lado mais antropológico da análise deste tipo de imagem não está inscrito, não se "vê", mas está implícito nos seus signos pictóricos, verbais ou formais. As figuras 6 e 9 são exemplos desse fenômeno.

Cabe mencionar que Julier (2006) critica o ocularcentrismo da cultura visual de Mirzoeff (1995), que, apesar de considerar o contexto sociocultural, se limita a analisar estritamente o que se vê, se abstendo de interpretações interdisciplinares. No domínio Valor, constatamos a construção de uma identidade coletiva, e a rede como ambiente propício para levantes ativistas. São valores individuais e coletivos, que expressam a ancestralidade, a cultura e a origem do artista/autor do card, assim como suas afinidades políticas, estéticas e sociais.

\footnotetext{
${ }^{3}$ Eduardo Navas (2016, p. 101-5) explica que as novas manifestações de linguagem da cultura regenerativa acontecem quando um elemento é reciclado de uma forma que seja reconhecível em uma nova proposta visual. A reciclagem desse material, disponível e apropriado nas redes, é a principal característica da cultura regenerativa. O regenerative remix funciona como uma ponte para o futuro da cultura na qual imagens, textos e sons efêmeros podem ser reaproveitados em diferentes propostas criativas.
} 


\section{Memória}

Nesta análise das imagens dissidentes das redes, Memória é o nome dado à intersecção entre os domínios Valor e Prática (Figura 3).

Figura 3: Intersecção do diagrama nomeada como Memória

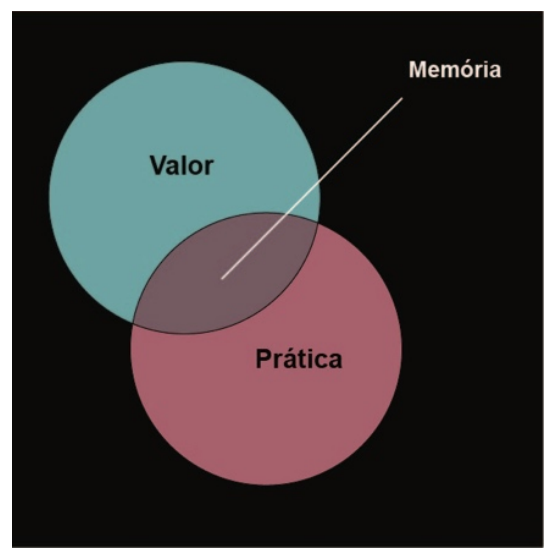

É no cruzamento dessas duas dimensões que conseguimos interpretar aspectos ligados à memória da imagem - seja a memória de acontecimentos factuais e históricos e de personalidades icônicas relacionadas a esses fatos, seja a memória afetiva do espectador, evocada pela imagem e relacionada às experiências pessoais. Além disso, há a associação semântica e visual que fazemos com outras peças de design gráfico que marcam nosso imaginário.

Incluir a memória em análises imagéticas nos permite agregar um componente subjetivo, que pode estar associado a outras simbologias e experiências afetivas. A memória também influencia quem faz a análise do objeto (o pesquisador) ou quem cria a peça gráfica. $E$ também afeta o receptor, quem vê e consome a imagem.

\section{Identidade e novas estéticas}

Para completar a interpretação dos novos conjuntos, denominamos "Identidade e novas estéticas" as intersecções entre Circulação e Valor (Figura 4). As linguagens visuais emergentes nas redes são marcadas pelo uso da ilustração vetorial, da colagem de fotografias e de desenhos manuais, além da apropriação de imagens documentais de outros períodos históricos para representar temas afins. Veremos exemplos desses cards a seguir. 
Figura 4: Intersecção do diagrama nomeado como Identidade e Novas estéticas

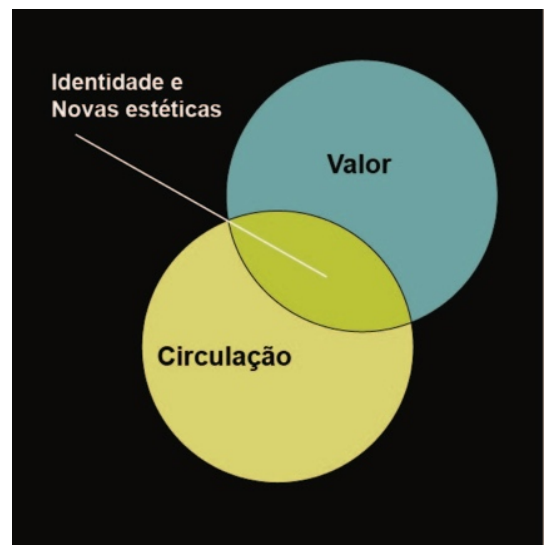

Na Figura 5, apresentamos a síntese da adaptação do diagrama de Julier. O card se destaca como peça gráfica central, resultado de todas as intersecções.

Figura 5: "A cultura do design e as imagens das redes": uma releitura do diagrama "Domínios da Cultura do Design", de Julier

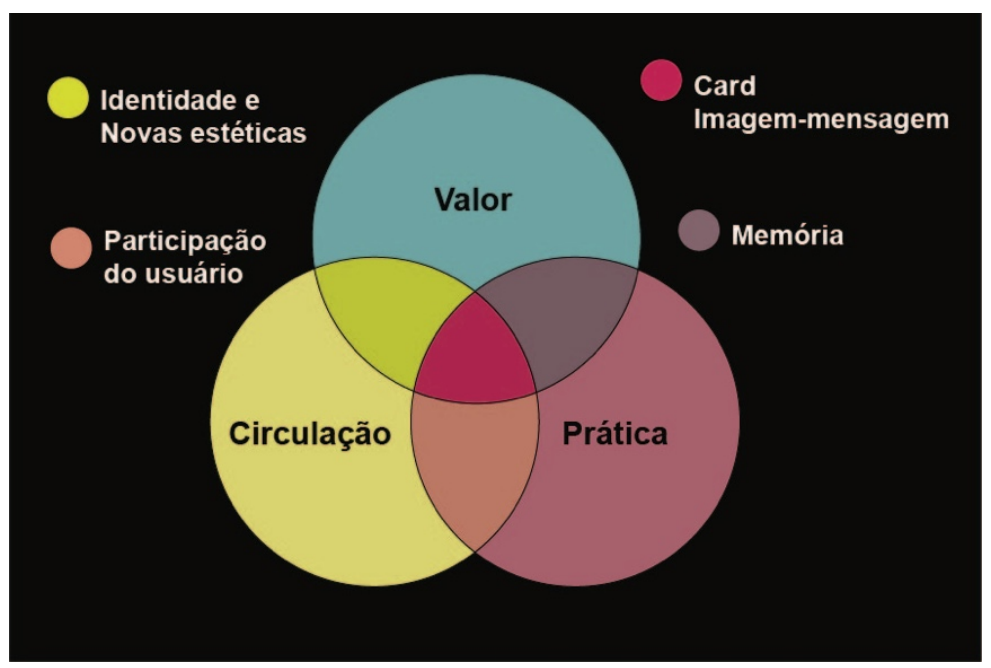

\section{Aplicação do diagrama "A cultura do design e as imagens das redes"}

É importante esclarecer qual metodologia foi adotada na seleção das imagens e porque se decidiu aplicar o diagrama da cultura do design à análise dos cards previamente categorizados como "ilustrações digitais" pela autora.

Como parte da pesquisa de doutorado em andamento, na qual é estudado o vocabulário estético das imagens dissidentes das redes, coube a aplicação de uma metodologia própria para a extração de uma base de dados de 40.000 imagens do Instagram, usando inteligência artificial. Primeiramente, por meio de uma edição cognitiva e empírica, definiram-se sete categorias: Ilustração digital; Ilustração manual; Ficção; Memes (subcategoria de ficção); Tipografia manual; Tipografia digital; e Apropriação. Com o uso de aprendizagem de máquina, 
a pesquisa pôde ampliar quantitativamente a amostra e a classificação de imagens, sendo "llustração digital" a categoria estética predominante.

A aplicação dos conceitos de Julier (2006) está sendo adotada em uma segunda etapa, com o objetivo de aprofundar a análise das novas estéticas das redes e todo o seu contexto interdisciplinar. A interpretação do diagrama original e a problematização desse novo vocabulário estético resultaram na proposta da nomenclatura para os conjuntos formados pelas intersecções do diagrama.

O critério de seleção dos cinco cards apresentados a seguir levou em consideração a diversidade de linguagens e experimentações gráficas que estes contêm - quão diversa pode ser a solução formal de uma ilustração digital. A combinação de diferentes técnicas (colagem, traços manuais digitalizados, uso de fotografias e patterns) e o uso da linguagem verbal na composição formal dessas peças representam a potência das novas estéticas emergentes nas redes. Além disso, as imagens foram extraídas de diferentes hashtags e representam o design de comunicação de diferentes causas ativistas.

$\mathrm{Na}$ Figura 6, a imagem capturada da hashtag \#elenao, publicada em 17/10/2018, representa a onda de extrema direita bolsonarista. A bandeira do Brasil invertida serve de carapuça, uma remissão explícita aos capuzes usados pelos membros da Ku Klux Klan, movimento reacionário e extremista americano. O uso da técnica de colagem - os olhos de Bolsonaro recortados de uma publicação impressa em preto e branco (com uma retícula particular às imagens reproduzidas de jornais) - realça o contexto factual e documental do card.

Figura 6: Imagem capturada da hashtag \#elenao, publicada em 17/10/2018.

Autor: Eduardo Foresti @foresti

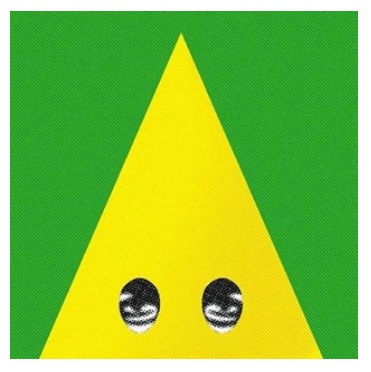

$\mathrm{Na}$ Figura 7, o card capturado pelas hashtags \#mariellepresente e \#designativista traz 0 retrato de Marielle e segue a mesma linguagem do cartaz que marcou a campanha de Barack Obama nas eleições americanas em 2008, desenhado pelo ilustrador e ativista Shepard Fairey. Esta peça gráfica é usada como referência de linguagem de ilustração e a estrutura da composição segue o mesmo padrão de diversos cartazes ilustrados com retratos de grandes personalidades políticas. A área inferior é destinada à linguagem verbal. Nesse caso, utilizaram-se letras da categoria "display", condensadas e caixa-alta, muito usadas e disponíveis no template do Instagram. A imagem viralizou e foi apropriada em milhares de outros posts sobre Marielle. 
Figura 7: Imagem capturada das hashtags \#mariellepresente e \#designativista, publicada em 14/3/2019 Autor: Cris Vector @crisvector

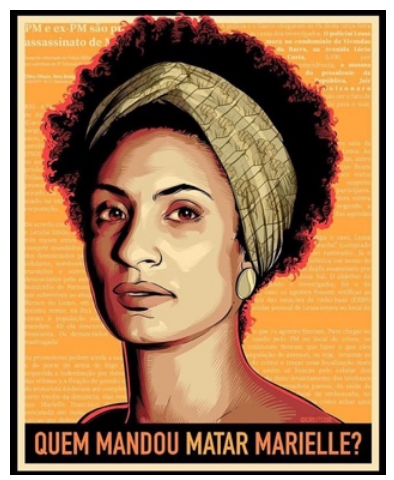

A Figura 8 faz uma paródia da frase "mais amor, por favor", letra de música sobre violência nas ruas da banda Preto no Branco (2016). Utiliza-se da linguagem verbal como elemento principal. O card explora tipograficamente questões binárias e faz parte de uma série de cards ativistas inspirados no design gráfico dos cartazes tipográficos suíços. A interferência digital, na inserção das marcas de tiro na palavra "arma", confere contemporaneidade à peça gráfica, mesclando linguagens.

Figura 8: Imagem capturada da hashtag \#desenhospelademocracia, publicada em 16/10/18. Autor: Bijari @bijari

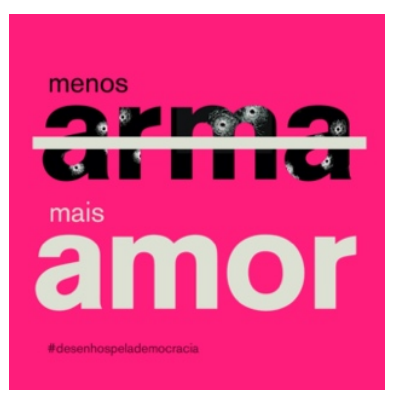

Figura 9: Imagem capturada da hashtag \#designativista, publicada em 15/2/2019.

Autor: Gladson Targa @gladsontarga

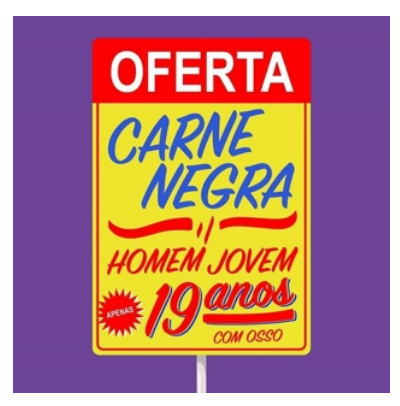

A Figura 9 faz uso da ironia para tratar do racismo e da brutalidade do assassinato de um jovem negro de 19 anos, morto pelo segurança do Hipermercado Extra na Barra da Tijuca, Rio de Janeiro, naquele dia. A peça gráfica se apropria da estrutura e da linguagem tipográfica dos 
cartazes de ofertas de produtos em supermercados e lojas populares, utilizando uma tipografia manual para o "anúncio".

Figura 10: Imagem capturada da hashtag \#designativista, publicada em 19/4/2019, data comemorativa do Dia do Índio. Autor: Mavi Morais @moraismavi

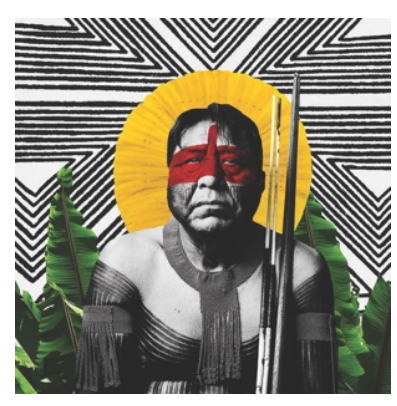

A Figura 10 é um bom exemplo das múltiplas linguagens utilizadas pelos artistas gráficos: a figura central é uma apropriação de uma fotografia em preto e branco de um índio (autor desconhecido/não fornecido), recortada e retrabalhada, com uma colagem de outros elementos fotográficos alegóricos, como o cocar e as bananeiras que compõem o cenário, reforçando o contexto cultural da imagem. O fundo é composto por uma ilustração vetorial, uma estampa de padronagem étnica/indígena.

\section{Considerações finais}

Ao propor a releitura do diagrama de Julier - interpretando os elementos analíticos da cultura do design e atribuindo novos significados possíveis às intersecções do diagrama estabeleceram-se novos parâmetros para o estudo das imagens que circulam nas redes sociais. Neste caso, o diagrama foi adaptado para ancorar os aspectos mais subjetivos e contextuais relacionados às imagens dissidentes do Instagram. Tais imagens, lidas pela lente do design de comunicação, careciam de uma análise mais diagramática, uma metodologia interdisciplinar que abarcasse outros aspectos inerentes a esses artefatos gráficos.

Figura 11: Síntese dos novos elementos para a análise das imagens-mensagens no Instagram

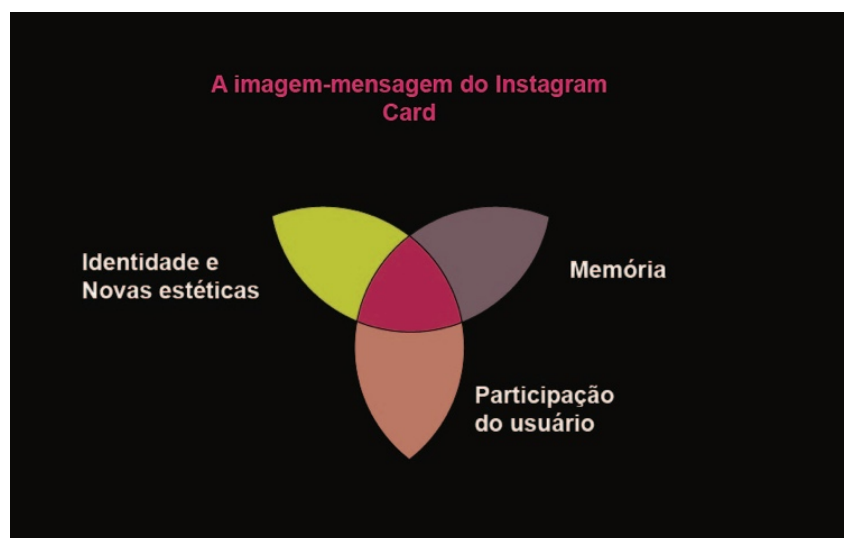


A versão ampliada do diagrama de Julier acrescenta novos elementos, denominados Participação do usuário; Memória; Identidade e Novas estéticas. As novas chaves interpretativas sugerem uma leitura das imagens ou peças gráficas que vão além dos aspectos formais e visuais. Essa abordagem, procura discutir os signos invisíveis perceptíveis pelo criador/emissor e pelo receptor. São elementos simbólicos a serem decifrados a partir do repertório de cada um.

Designar um nome aos interstícios dos grandes domínios Circulação, Valor e Prática propostos pela cultura do design é uma maneira de acrescentar novas camadas interpretativas (e essenciais) ao estudo das narrativas visuais contemporâneas. Os cards representam artefatos gráficos digitais, fruto de uma nova cultura de design e de uma manifestação de linguagem de comunicação em rede. Escapam dos quesitos propostos pelas análises gráficas pensadas a partir de uma concepção formal e estática, com um grid preestabelecido - herança dos dogmas projetuais do design moderno.

Os cards vão além, pois reúnem espacialmente e de forma pictórica um emaranhado de tempo de influências visuais e estilísticas, plasmadas em uma mesma imagem de formato reduzido. E podem ser considerados uma peça em constante transformação, devido à participação do usuário e sua circulação (com legendas/hashtags que os deslocam nas redes). À luz de práticas de produção gráfica dissidentes, podem ser considerados uma evolução cultural, contextual e tecnológica dos cartazes dissidentes produzidos mundialmente em outros períodos da história.

O acesso às tecnologias e o uso de dispositivos móveis e de aplicativos celulares são fatores determinantes para a criação e circulação de peças gráficas contemporâneas. A grande variedade de tipografias, de ilustrações e de imagens "ready to use" e os mecanismos de busca de imagens em um clique contribuem para o surgimento de uma linguagem remixada, baseada na estética da adição.

Além disso, o acesso às técnicas ilustrativas, sobretudo das ilustrações vetoriais, cria oportunidades para o surgimento de novos talentos, ilustradores criativos que emergem nas redes. No contexto de superprodução de imagens, passíveis de serem esquecidas no fluxo midiático, é fundamental analisar e catalogar amostras das novas representações estéticas.

A proposta do diagrama "A cultura do design e as imagens das redes" poderá ser aplicada em outros estudos relacionados ao design de informação no campo da comunicação, da história do design e da cultura material. Nesse sentido, o presente trabalho pretende contribuir para a interdisciplinaridade dos estudos relacionados à cultura visual contemporânea, às narrativas visuais digitais. A subjetividade interpretativa do pesquisador (designer, semiólogo, historiador) ou do algoritmo (treinado por homens) terá sempre um viés. Cabe a nós, designers e pesquisadores, identificar as potencialidades de cada metodologia, contribuindo com novas perspectivas interpretativas para uma compreensão mais sistêmica do design de comunicação das redes. 


\section{Referências}

Beiguelman, G. (2019). Memória da amnésia: políticas do esquecimento. São Paulo: Edições Sesc.

Boylan, A. (2020). Visual culture. Cambridge: MIT Press.

Braga, M., \& Farias, P. (2018). Dez ensaios sobre memória gráfica. São Paulo: Blucher.

Didi-Huberman, G. (1998). O que vemos, o que nos olha. São Paulo: Editora 34.

Grau, O. (2010). Media art histories. Cambridge: MIT Press.

Grau, O. (2013). Imagery in the 21st Century. Cambridge: MIT Press.

Julier, G. (2006). From visual culture to design culture. Design Issues, 22(1),64-76.

Margolin, V. (1994). Narrative problems of graphic design history. In: Visible languages. Chicago: University of Chicago Press.

Margolin, V. (2014). Problemas narrativos da história do design gráfico, 2014. In: A política do artificial: Ensaios e estudos sobre design. Rio de Janeiro: Civilização Brasileira.

Menezes, U. (2003). Fontes visuais, cultura visual, história visual: Balanço provisório, propostas cautelares. Revista Brasileira de História,23(45), 11-36.

Mirzoeff, N. (1999). An introduction to visual culture. London: Routledge.

Mirzoeff, N. (2009). Global visual cultures. London: Pelican Books.

Navas, E. Regenerative culture. Norient Academic Online Journal. Disponível em: $<$ https://norient.com/tag/regenerative-culture-part-15>. Acesso em: jun. 2017.

Paul, C. (2011). Contextual networks: data identity and collective production. In: Lovejoy, M. et al. (eds.). Context providers: conditions of meaning in media arts. Bristol,UK/Chicago, EUA: Intellect.

Prata, D., Cozman, F., \& Polleti, G. (2020). Using Al to classify Instagram's dissident images. Proceedings of the 12th International Conference on Design History and Design Studies (ICDHS), Zagreb,695-708.

Ranciére, J. (2005). A partilha do sensível: estética e política. São Paulo: Editora 34.

Ranciére, J. (2013). O destino das imagens. Rio de Janeiro: Contraponto.

Vesna, V. (2007). Database aesthetics: Art in the age of information overflow. Minneapolis: University of Minessota Press.

\section{Sobre a autora}

Didiana Prata, doutoranda do Curso de Pós-Graduação em Design da FAU-USP. didianaprata@usp.br 